\title{
HISTORIOGRAFIA ISLÂMICA CLÁSSICA: AS NARRATIVAS SOBRE OS PRIMEIROS ANOS DO ISLÃ
}

\section{CLASSICAL ISLAMIC HISTORIOGRAPHY: THE NARRATIVE OF THE FIRST YEARS OF ISLAM}

DOI: http//dx.doi.org/10.15448/21778-3748.2018.2.26214

\author{
Michele Rosado de Lima Castro \\ Mestranda em História - Unicamp \\ michelerosado.his@gmail.com
}

\begin{abstract}
RESUMO: Esse trabalho tem como objetivo apresentar algumas características dos textos históricos produzidos no mundo islâmico ao longo dos séculos VIII, IX e X, bem como discorrer acerca dos principais problemas debatidos entre os historiadores contemporâneos sobre sua utilização como fontes para seus estudos sobre os primeiros anos do Islã. Os textos a que nos referimos constituem um valioso conjunto de documentos históricos, visto que são os mais antigos textos que chegaram até nós escritos pelos próprios muçulmanos sobre seu passado e sobre as origens de sua religião. No entanto, há algumas características que suscitam problemas para os historiadores do tema, como, por exemplo, o fato de não serem relatos contemporâneos aos acontecimentos e a forma como essas narrativas foram construídas. Na primeira parte do texto, apresentaremos as considerações dos historiadores acerca do surgimento do interesse pela história entre os árabes. Na segunda parte, apontaremos as principais características desses textos e abordaremos outros dois problemas debatidos na historiografia atual sobre o tema: podemos chamar os escritores desses textos de autores? Podemos confiar nas informações fornecidas por esses textos sobre os primeiros anos do Islã? Finalmente, na terceira parte, tentaremos nos posicionar diante dos debates apresentados para, ao final, propormos uma forma de abordagem desses textos como fontes históricas.
\end{abstract}

PALAVRAS-CHAVE: Islã Clássico; Historiografia; Autoria.

ABSTRACT: The objective of this work is to present some characteristics of the historical texts produced in the Islamic world though the $8^{\text {th }}, 9^{\text {th }}$ and $10^{\text {th }}$ centuries, as well as discuss some of the main debates among the contemporary historians referring the use of those texts as historical sources for the studies of the first years of Islam. The texts we mention here form a great set of historical documents as they are the oldest ones written by the Muslims about their own past that have survived until our days. Nevertheless, some historians of Medieval Islam find on them some problems such as the fact they are not contemporaneous to fact they narrate and the form that the narratives were built. In the first part of this paper, we will present the historians's observations about the beginnings of an interest for history among the Arabs. In the second part, we will point the main characteristics of those texts and approach two problems currently discussed among the historians of the theme: Is it correct to refer to those scholars as authors? Can we trust the information provided by those texts about the first years of Islam? At last, in the third part, we will express our own considerations about the debates presented and propose a way to approach those texts as historical sources.

KEYWORDS: Classical Islam, Historiography, Authorship. 


\section{O SURGIMENTO DA HISTORIOGRAFIA ISLÂMICA}

Assim como em francês, inglês, português e entre outras línguas, a palavra em árabe para história, tārīkh, também abrange dois significados diferentes: aquele da passagem do tempo e aquele da investigação do passado. Todas as sociedades estão ou estiveram sujeitas ao processo histórico, mas nem todas têm ou tiveram interesse em investigar a passagem do tempo, os acontecimentos, suas causas e consequências, transformações e permanências. Não cabe a nós, historiadores, fazer qualquer tipo de julgamento no sentido de determinar se a preocupação com a escrita da história seria ou não algo que caracteriza sociedades como mais avançadas ou mais primitivas, mas nos é importante pensar a respeito dos fatores que motivam a transformação de sociedades que têm pouca ou nenhuma preocupação com a racionalização da passagem do tempo em sociedades que pensam sua passagem de forma sistematizada e produzem reflexões sobre ele.

No caso dos árabes, é interessante destacar que a palavra tārīkh sequer parece ter existido antes do surgimento do Islã (ROSENTHAL, 1968, p. 13), ou, se existiu, significava algo relativo a tempo, mas não "história" como passou a designar posteriormente (QURESHI, 1966, p. 1196.). Apesar dos filólogos ainda não conseguirem precisar a origem exata da palavra, sabe-se que sua raiz também está presente em outras línguas semitas que significam "lua" ou "mês", além de também ser similar ao termo plural para "datas" usado em dialetos no Sul da Península Arábica (DE BLOIS, 2000, vol. 10, p. 257). Seu uso com o sentido de "escrita da história" só começou a aparecer por volta de dois séculos após a hégira ${ }^{1}$ (DE BLOIS, 2000, vol. 10, p. 271), justamente quando a maioria dos grandes trabalhos de história começaram a ser produzidos, como veremos adiante.

Outro termo que aparece com frequência para designar a narrativa sobre o passado é $a k h b \bar{a} r$ (plural de khabar) que significa relatos, narrativas e antecede o uso da palavra tārīkh. Os dois termos não são sinônimos, akhbār normalmente são relatos curtos, escritos ou orais, sobre um evento específico e nem sempre contém informações sobre datas ou relações de causalidade com outros eventos. Em alguns deles, há somente a informação sobre algo que alguém falou ou fez sem conter detalhes sobre o contexto em que aquilo se passou. A recuperação de acontecimentos históricos só poderia acontecer a partir da união e organização

\footnotetext{
${ }^{1}$ Hégira é a migração de Muhammad com seus primeiros seguidores da cidade de Meca para Medina em 622 devido à opressão dos coraixitas (quraysh), tribo dominante em Meca naquele momento. Este ano marca o início do calendário islâmico. Neste trabalho, sempre que possível indicaremos anos e séculos tanto no calendário islâmico quanto no calendário gregoriano, separados por uma barra (/), assim, séc. III/IX significa século III no calendário islâmico e IX no gregoriano.
} 
de vários desses relatos a fim de produzir algum significado para aqueles que não presenciaram os eventos tratados. Esse trabalho de coleta e organização e transmissão dessas akhbār, feito através de um misto entre escrita e oralidade (SCHOELER, 2006, p. 28-45), começou a ser colocado em prática cerca de um século após a hégira por estudiosos que se interessaram em narrar o passado da comunidade.

Em muitos casos, esses autores denominavam seus próprios trabalhos a partir do tema sobre o qual pretendiam escrever: Ibn Ishaq (m. 150/761) redigiu a primeira biografia (Sïrah) de Muhammad, intitulada Sìrat Rasūl Allah (Biografia do Mensageiro de Deus); Abu Mikhnaf², escreveu seu trabalho sobre a conquista (futūh) da Síria chamada Futūh al-Shām. Posteriormente, trabalhos que receberam de seus próprios autores o nome de tārīkh também começaram a aparecer, o mais famoso deles é o de al-Ṭabari (m. 310/923) com sua Tārīkh alRusūl wa al-Mulūk (História dos Profetas e Reis), na qual reuniu relatos que trataram de assuntos desde a criação do mundo até os acontecimentos de seus próprios dias.

Um importante debate entre historiadores contemporâneos acerca da produção historiográfica nos primeiros séculos do Islã trata do momento em que surge entre os árabes uma consciência histórica. Parece ser um consenso entre os estudiosos que o surgimento dessa “consciência” está diretamente ligado ao surgimento da religião e da comunidade muçulmana. Segundo a análise desses autores, nos textos árabes pré-islâmicos havia dois estilos principais, a poesia e o ayyām al- 'arab (algo como Dias de Luta dos Árabes), em que se narravam batalhas entre tribos. Tais composições tinham pouca preocupação com o tempo: eventos do passado eram narrados, mas não era necessário estabelecer o momento em que aconteceram ou as relações com outros eventos, já que seu fim último era a moralização ou a exaltação de determinadas tribos ou personalidades. Ambas eram tanto recitadas quanto transmitidas de forma oral ${ }^{3}$.

No entanto, apesar do aparente consenso a respeito da Arábia pré-islâmica, o mesmo não é verdade quando se fala sobre o momento em que esse interesse pela história teve início. Muitos dos grandes historiadores do Islã medieval acreditam que foi o próprio Muhammad e suas mensagens que despertaram a consciência histórica nos árabes. As três grandes religiões monoteístas compartilham inúmeras características em relação a seus textos sagrados e seus dogmas e uma delas é a noção de que o mundo que conhecemos terá um fim e neste momento

\footnotetext{
${ }^{2}$ Muitos autores do século III/IX em diante dizem ter usado este trabalho como base, mas não se pode ter certeza porque a obra propriamente dita não chegou até nós.

${ }^{3}$ Sobre as características da poesia e do ayyām al- 'arab e seu caráter a-histórico conferir KHALIDI, 1994, p 1-8; ROSENTHAL, 1968, p 18-23.
} 
todos os seres humanos serão julgados de acordo com suas ações em vida. Assim, pode-se considerar que as noções de Fim dos Tempos e de Julgamento Final presentes nas mensagens de Muhammad tenham inserido os muçulmanos no tempo histórico e criado uma relação direta entre presente e futuro, já que o que se faz no presente será avaliado no futuro e determinará como será a vida no mundo espiritual. Para Franz Rosenthal, a avaliação do presente que a noção de Julgamento Final torna necessária traz consigo também uma análise dos valores das ações do passado, o que o autor identifica como um dos primeiros estímulos para o estabelecimento de um "pensamento histórico" (ROSENTHAL, 1968, p. 25-26). Ao mesmo tempo, as mensagens transmitidas por Muhammad o identificam como o último dos profetas que foram enviados por Deus para guiarem Seu povo. Segundo a narrativa do Corão, alguns desses profetas tiveram sucesso em sua missão enquanto outros falharam e, assim, Muhammad foi enviado para trazer uma mensagem permanente, confirmar ou retificar as anteriores (Alcorão, 5:44-47; 6:92; 2:89) e corrigir possíveis erros de interpretações das mensagens de seus antecessores (Alcorão 2:216). Rosenthal enfatiza que Muhammad está "historicamente conectado" com a sucessão dos profetas e "somente os triunfos e derrotas do passado fizeram de Muhammad o que ele foi" (ROSENTHAL, 1968, p. 26). Assim, para o autor, a própria posição de Muhammad é histórica e incentiva a investigação do passado pela comunidade.

A argumentação de outro grande historiador do Islã Medieval, Tarif Khalidi, vai ao encontro da de Rosenthal e defende que "o islã e a história são coevos” (KHALIDI, 1994, p. 8). Ele considera que no Corão a relação de Deus com o homem é baseada em registros históricos, um registro de erros e acertos passados. Além disso, argumenta que a presença do binômio memória/esquecimento desempenha papel fundamental nas mensagens do Corão. Segundo sua interpretação, o homem é, através da repetição dos momentos históricos presentes no Corão, impelido por Deus a se lembrar. O Corão repete histórias com o mesmo teor moral com frequência, o que, para Khalidi, é um apelo à memória. $\mathrm{O}$ crente deve se lembrar das consequências que sofreram aqueles que não acreditaram nas mensagens dos profetas enviados e como foram salvos aqueles creram em Deus. Por outro lado, o pecado ocorre quando o homem se esquece, "é como se a luta cósmica entre o bem e o mal fosse travada na memória do homem" (KHALIDI, 1994, p. 12).

Um caminho um pouco distinto é traçado, quatro anos após o lançamento da obra de Khalidi citada acima, pelo americano Fred McGraw Donner. Em sua obra Narratives of Islamic Origins, o autor defende que tanto o Corão quanto os primeiros muçulmanos se interessavam muito pouco por questões históricas. Segundo ele, “a perspectiva do Corão é histórica somente 
no sentido muito geral de que o homem parece existir entre dois pontos definidos no tempo, a Criação e o Julgamento Final” (DONNER, 1998, p. 80), o enfoque do Texto Sagrado está, sobretudo, nas noções de moralidade e piedade, sobre as quais a comunidade será confrontada eternamente. Segundo sua interpretação, esse aspecto eterno da moralidade e da piedade fazem com que o "conceito de história seja fundamentalmente irrelevante para o Corão" (DONNER, 1998, p. 80). O amparo material de sua argumentação está nas narrativas do próprio Livro, como também é o caso dos historiadores já citados. Onde os outros autores veem um conjunto de material histórico, já que são narrativas sobre o passado, Donner vê narrativas fragmentadas que só podem ser reconstruídas, quando o podem, se seus pedaços dispersos forem coletados ao longo do texto e remendados para construir uma narrativa coerente (DONNER, 1998, p. 81). Esse comentário não significa, no entanto, que o autor acredite que as narrativas do Corão não consigam transmitir as mensagens desejadas, mas, ao contrário, pretende mostrar que mesmo com relatos fragmentados elas atingem muito bem seu objetivo, que é o de moralização. Para alcançar tal fim, não é necessário que as narrativas possuam coerência histórica, que os episódios, povos ou situações estejam localizados no tempo ou organizados sequencialmente, já que mesmo sem essas características as narrativas podem prover o crente de exemplos "da escolha moral eterna entre crença e descrença, o bem e o mal" (DONNER, 1998, p. 81), o que é, para Donner, o objetivo final do texto.

Segundo a interpretação do autor, o mesmo acontece com os textos produzidos nas primeiras décadas do Islã: eles não indicam grande interesse pela história. Apesar do número de fontes deste período que sobreviveu até os dias de hoje ser extremamente limitado, o autor identificou a repetição de alguns assuntos específicos: elas "contém principalmente frases de piedade, pedidos de perdão divino, declarações enfáticas da unidade e unicidade de Deus e, raramente, citações ou paráfrases do Corão" (DONNER, 1998, p. 85). Elas não incluem, por outro lado, "afirmações do chauvinismo tribal, expressões de reivindicações políticas de grupos rivais, expressões evidentes de uma identidade confessional islâmica, e declarações de teor teológico além da afirmação geral da unidade de Deus" (DONNER, 1998, p. 88). Essa afirmação pode causar surpresa, pois é recorrente entre os estudiosos a ideia de que uma grande preocupação dos muçulmanos logo após a morte de Muhammad era preservar a memória do profeta, o que logo suscitou um interesse pela pesquisa histórica ${ }^{4}$. No entanto, Donner apresenta materiais como escritos particulares, grafites e escritos oficiais que questionam a precisão dessa afirmação. Ainda mais surpreendente é o fato de que, segundo ele, esses primeiros escritos

\footnotetext{
${ }^{4}$ Essa afirmação comum pode ser vista, por exemplo, em QURESHI, 1966, p 1200-1202
} 
muçulmanos raramente mencionavam Muhammad e a primeira menção a ele foi em uma moeda datada de 66 AH em Bishapur, cidade antiga no Sudoeste do atual Irã (DONNER, 1998, p. 81). Segundo a interpretação do autor, somente mais tarde a comunidade começou a identificar os eventos relacionados a Muhammad, seu papel como profeta e o processo de revelação, como geradores de uma tradição (DONNER, 1998, p. 113-114).

Em nossa interpretação, a argumentação de que Muhammad e suas mensagens inserem os árabes em uma história em que passado, presente e futuro - e a relação entre os três - ganham uma dimensão diferente não perde a importância diante dos questionamentos de Donner. Tampouco se pode negar que a posição de Muhammad - como último dos profetas e como homem de grande caráter moral a tal ponto que Corão recomenda que sua vida seja usada como exemplo de correção (Alcorão 33:21) - tenha servido de incentivo à pesquisa histórica. No entanto, o trabalho de Donner traz um questionamento extremamente importante. Essas características do Profeta do Islã e do Livro Sagrado são relevantes e parecem ser suficientes para suscitar uma transformação na forma como aquelas pessoas olhavam e se relacionavam com o tempo, bem como para incentivar o início da investigação histórica, porém duas perguntas se fazem necessárias: quando saímos do campo da teorização, essas mudanças realmente aconteceram? Se sim, aconteceram de forma imediata ou de forma gradativa?

As fontes antigas nos mostram que a resposta para a primeira pergunta é positiva. Não há dúvida que essas mudanças aconteceram e que elas foram motivadas pelas mensagens de Muhammad e por sua própria história, já que o desenvolvimento da historiografia islâmica esteve sempre ligado a questões religiosas. A contribuição do trabalho de Donner no assunto está principalmente na segunda questão proposta: essas mudanças não parecem ter sido tão imediatas como se assumia. A ruptura dos árabes com o modo de vida praticado por eles antes da difusão das mensagens de Muhammad se deu de forma gradativa. Além disso, nos parece importante acrescentar que a noção de estar inserido em uma espécie de progressão histórica como é a noção histórica das três grandes religiões monoteístas - e a transformação da percepção entre a relação de passado, presente e futuro não implica necessariamente em uma necessidade imediata de investigação histórica.

Para Donner, a investigação histórica e sua eventual escrita surgiu entre os árabes em decorrência do contato e da convivência da ummah (Comunidade dos Muçulmanos) com outras comunidades religiosas. Ao longo dos anos 20 e $30 \mathrm{AH}$ (por volta das décadas de 630 e 640 d.C), a comunidade passou possuir territórios fora da Península Arábica, precisando estabelecer um governo em locais anteriormente cristãos, judeus ou zoroastrianos. No início, é possível que 
a relação com as outras religiões tenha sido harmoniosa, mas com o passar do tempo os muçulmanos começaram a questionar dogmas das outras religiões da mesma forma que tiveram suas próprias crenças questionadas. Para Donner, isso tanto causou o início do processo de formação da identidade confessional muçulmana como algo marcadamente distinto das outras religiões monoteístas ${ }^{5}$, quanto motivou o início da utilização de fatos históricos para legitimar, por exemplo, o papel de Muhammad como verdadeiro profeta, as revelações como verdadeiras palavras de Deus e a posição da comunidade como eleita por Deus para governar outras.

Anteriores ao uso da história como ferramenta de legitimação, o autor aponta duas outras: a legitimação pela genealogia e a legitimação pela piedade. Segundo sua análise das fontes, o uso da primeira pode ser localizado ainda na Arábia pré-islâmica, nas composições de ayyām al-'arab, como mencionamos anteriormente. A segunda ferramenta parece ter sido amplamente utilizada para resolver as primeiras situações de conflito da comunidade, já que as fontes mostram que questões como associações históricas ou questões tribais não apareceram naquele momento (DONNER, 1998, p. 98). Assim, em sua concepção, o interesse pela história surgiu em momentos de conflito e serviu como ferramenta de legitimação, em um primeiro momento, da ummah diante de outras comunidades e, posteriormente, entre grupos dentro da própria ummah.

\section{AS CARACTERÍSTICAS DOS TEXTOS HISTORIOGRÁFICOS ISLÂMICOS}

\section{CLÁSSICOS}

Entre as primeiras obras $^{6}$ de história da comunidade muçulmana que temos conhecimento, as mais antigas são as de 'Urwah b. al-Zubayr (m. 93-94/711-13) e al-Zuhrī (124/741-2), ambos de Medina, escreveram sobre a vida de Muhammad e seus trabalhos só são conhecidos porque sobreviveram através de citações de autores posteriores. Outro exemplo é o

\footnotetext{
5 Donner também se opõe à interpretação amplamente aceita pela historiografia de que a identidade desses primeiros muçulmanos como pertencentes à uma religião distinta das outras surgiu já nos primeiros anos da religião. Para ele, os primeiros seguidores de Muhammad se viam como uma "Comunidade de crentes" que compartilhavam a visão de Muhammad da unicidade de Deus e do Fim dos Temos e acreditavam na necessidade de se prepararem para esse fim. A esse respeito, conferir DONNER, 2003.

${ }^{6}$ Para a discussão sobre o formato dessas obras - se possuía um conteúdo fixo formalizado em um livro propriamente dito ou se era transmitido através de um misto entre escrita e oralidade e, por isso, seu conteúdo era mais fluido - conferir SCHOELER, 2006.
} 
do já citado Ibn Isḥaq, que morreu na segunda metade do século II/VIII, cujo trabalho sobre a vida de Muhammad sobreviveu até nossos dias ${ }^{7}$. O fato de todas essas primeiras obras constituírem biografias de Muhammad não é uma coincidência e parece ser um dos fatores que levam muitos historiadores a interpretarem o papel do Profeta e de suas mensagens como principais motivos do surgimento da consciência histórica entre os árabes. Outra razão que fundamenta essa afirmação certamente é o fato de que a investigação do passado e a posterior produção historiográfica está intimamente ligada com o que se conhece como Hadīth.

Hadìth (no plural ahādīth) é uma das palavras usadas no Corão para se referir à narração do passado. Em conformidade com sua argumentação de que o texto corânico por si só já estimula a investigação histórica, Tarif Khalidi, afirma que o significado da palavra hadīth no Corão vai sendo modificado com o passar do tempo. Segundo ele, nas suras ${ }^{8}$ reveladas em Meca a palavra aparece indicando um sentido mais próximo de "parábola" enquanto que nas de Medina adquire o sentido de "fala" ou "relato". Em sua interpretação, isso indica uma mudança de função, passando de aplicação mais privada para outra mais pública como guia da comunidade (KHALIDI, 1994, p. 18). A afirmação de que a utilização de relatos do passado como guia para os crentes encontra fundamentação no Corão infelizmente não é seguida de referências do próprio Texto Sagrado que possam confirmá-la e ainda carece de uma análise aprofundada. No entanto, seja como ferramenta de guia da comunidade, seja como forma de legitimar um ponto de vista ao atribuí-lo a autoridades religiosas do passado, como é na interpretação de Donner (1998, P. 256), é certo que em algum momento ao longo do primeiro século do Islã essas narrativas do passado foram amplamente utilizadas. O termo precedido do artigo definido, al-hadìth, passou a se referir especificamente aos relatos sobre os atos e falas de Muhammad e usado para solucionar problemas a respeito da interpretação de alguma parte mais obscura do Corão ou para estabelecer regras sociais que não constavam ali.

Esses relatos podiam ser feitos de forma escrita ou oral e, como estavam diretamente ligados à vida moral e religiosa do crente, precisavam de alguma forma de autenticação. $\mathrm{O}$ primeiro aparato crítico utilizado era a citação da cadeia de transmissão (isnād) que, devia especificar todas as pessoas pelas quais aquela informação passou e ao, final, remeter àquele que viu ou ouviu o acontecimento relatado. A autenticidade da $i s n \bar{d}$ era avaliada de acordo

\footnotetext{
${ }^{7}$ A tradução mais conhecida dela para línguas modernas ocidentais é a inglesa de Alfred Guillaume datada de 1955. Cf.: GUILLAUME, 2004.

${ }^{8}$ O Corão é dividido em 114 suras, que, por sua vez, são divididas em ayat ou versículos. Algumas suras foram reveladas em Meca, antes da hégira, e outras em Medina. No Corão, elas são organizadas das mais longas para as $\underline{\text { mais curtas e não de forma cronológica. }}$
} 
com a notoriedade de seus transmissores (muhaddìth) e o respeito que eles inspiravam na comunidade. Além disso era analisado quando o muhaddìth nasceu e morreu para determinar se era mesmo possível que ele tivesse conhecido a pessoa citada. É importante ressaltar que um muhaddith considerado relevante para um grupo podia não ser para outros. Um exemplo disso é que xiitas rejeitam os relatos de 'Ā'ishah, esposa de Muhammad que se opôs a 'Ali na Batalha do Camelo ${ }^{9}$, enquanto que para os sunitas eles normalmente são considerados altamente confiáveis.

Apesar da oposição de parte da comunidade que acreditava que hadīth não poderia ser escrita porque ameaçaria o status do Corão como detentor da $\operatorname{Verdade}^{10}$, ela foi se cristalizando como um dos pilares da sociedade. Ao longo do primeiro século e meio, eram transmitidas oralmente e por vezes escritas em pergaminhos, a partir do século III/IX começaram a ser compiladas em livros e divididas por temas. As mais reconhecidas compilações de Hadīth são a de Muhammad bin Ismā il al-Bukhārī (m. 870) e a de Abu al-Husayn Muslim bin al-Hajjāj (m. 875). Com o passar do tempo hadìth se tornou a segunda fonte de conhecimento da comunidade, atrás somente do Corão, e um dos pilares da sharī $a$ (lei islâmica).

Os trabalhos de história que começaram a surgir a partir do século II/VIII, e se tornaram mais numerosos a partir do século III/IX, seguiram um modelo muito semelhante ao da hadīth, já que se acreditava que o conhecimento do passado só poderia ser acessado se fosse recontado por aquelas pessoas que o presenciaram ${ }^{11}$. Tais obras eram, então, compostas por relatos transmitidos ao longo do tempo organizados cronologicamente e sempre continham a forma de autenticação comum no formato de hadīth, a isnād. Muitas vezes, esses trabalhos eram

\footnotetext{
${ }^{9} \mathrm{~A}$ crença mais fundamental dos xiitas é que a comunidade deveria ser liderada somente por parentes do Profeta. Muhammad morreu em $632 \mathrm{sem}$ deixar filhos homens, seu parente mais próximo era 'Ali, seu primo e genro, que, para esse grupo, deveria se tornar califa. De acordo com essa visão, os três califas que lideraram a comunidade antes de 'Ali, Abū Bakr (632-634), 'Umar (634-644) e Uthmān (644-656), usurparam o poder daquele que era o líder legítimo. Quando finalmente chegou ao governo, em 656, 'Ali enfrentou grande oposição de grupos que o acusavam de estar envolvido com o assassinato do califa anterior e, por isso, teve que travar diversas batalhas para defender seu califado. Uma delas, conhecida como Batalha do Camelo e travada alguns meses após ter sido escolhido califa, foi contra Ā'ishah, esposa de Muhammad e muito respeitada pela comunidade, e dois importantes Companheiros do Profeta, Țalhah e Zubayr.

${ }^{10}$ Verdade com letra maiúscula porque se refere ao conhecimento ( ${ }^{\mathrm{i}} \mathrm{lm}$ ) enviado por Deus através das mensagens de Muhammad.

${ }^{11}$ Essa afirmação está presente na introdução da tārīkh de al-Ṭabari em que ele diz: "O leitor deve saber que com relação a tudo que mencionei e estipulei ser escrito nesse nosso livro, eu me baseei em tradições e relatos que eu transmiti e que eu atribuo a seus transmissores. Eu me valho somente muito raramente do conhecimento adquirido através de argumentos racionais e produzidos por processos internos de pensamento. Porque nenhum conhecimento sobre a história dos homens do passado e dos homens e eventos recentes é atingível por aqueles que não puderam presenciá-los e não viveram no tempo em que ocorreram, exceto através da informação e da transmissão fornecida por informantes e transmissores. Esse conhecimento não pode ser acessado através da razão ou produzido por processos internos de pensamento". Cf. AL-TABARI, 1989, Vol. 1. p. 170.
} 
criticados por estudiosos e críticos de hadīth porque nem sempre seus autores apresentavam a isnād da forma como um muhaddìth esperava.

É importante ressaltar que mesmo que escritos e livros propriamente ditos tenham sido produzidos ao longo do século II/VIII, como é o caso, por exemplo, dos trabalhos de Abu Mikhnaf (m. 157/773-774) e Sayf b. 'Umar (m. 180/796) e outros já citados anteriormente, a maioria deles não sobreviveu até os dias de hoje. Aqueles que sobreviveram, como é o caso da Sìrah de Ibn Isḥaq, foi somente através de edições de séculos posteriores. Assim, o que se conhece acerca desses primeiros trabalhos de história está, em grande medida, ligado a seu uso pelos estudiosos de séculos posteriores.

A produção escrita no mundo árabe-islâmico é normalmente dividida em três períodos, tal como a proposta por Chase F. Robinson, em sua obra Islamic Historiography. Segundo ele, a primeira fase se estendeu desde o início das revelações de Muhammad até os primeiros anos do século II (década de 30 do século VIII) em que a oralidade ainda prevalecia e a escrita era usada com mais frequência para questões de estado (tratados, administração de impostos, etc), para sermões e cartas. A segunda fase foi aquela que é considerada como a que deu início ao processo de produção historiográfica, vai do início do século II/VIII até o início do século III/IX. Nesse momento, as tradições que circulavam tanto de forma oral quanto escrita foram sendo compiladas em obras que formavam os livros. A terceira fase foi aquela em que a maioria das obras que conhecemos hoje foi escrita, se estendeu do início do século III/IX até o início do século IV/X. Nesse período houve tanto uma grande produção de volumosas obras de história quanto a edição e reprodução de manuscritos antigos. Um exemplo do primeiro fenômeno é a já citada tārīkh de TTabari, cuja extensão pode ser percebida através de sua tradução completa para o Inglês, terminada nos anos 2000, totalizando 39 volumes. Um exemplo do segundo é a também já citada Sìrah de Isḥaq que foi editada por Ibn Hishām no início do século III/IX e se tornou a versão definitiva da obra ${ }^{12}$.

As características das obras desse período normalmente suscitam dois problemas importantes entre os historiadores contemporâneos. O primeiro diz respeito a questão da autoria: se esses textos são compilações de relatos anteriores, podemos chamar os estudiosos que as produziram de autores ou simplesmente de compiladores? A segunda questão é sobre a

\footnotetext{
${ }^{12}$ Para a divisão feita por Robinson, ver: ROBINSON, 2003, p 20-38. Com o objetivo de dar ênfase à noção já discutida de que os primeiros muçulmanos tinham pouco ou nenhum interesse pela investigação histórica, Donner propõe uma divisão um pouco diferente. Ele chama os primeiros 50 anos de fase "pré-historicista", seguindo pela "proto-historicista" que iria até o fim do século I. A primeira metade do século II é chamada de "primeira fase letrada" seguida pela "fase letrada tardia" em que foi produzido o que se conhece como historiografia islâmica clássica. Cf. DONNER, 1998 p 276-282.
} 
autenticidade das informações que temos sobre as origens do Islã e os acontecimentos do primeiro século: se praticamente tudo o que se conhece sobre esse período está em função dos escritores de séculos posteriores, é possível afirmar que esses textos podem servir como fonte de informações autênticas sobre esses primeiros anos do Islã ou eles só podem ser usados como fonte de informações sobre o tempo em que foram escritos?

Sobre o problema da autoria, é interessante notar que ele também está presente nos próprios textos dos escritores do período. Vejamos um trecho da introdução da tārīkh de Ṭabari:

Esse nosso livro pode conter algumas informações mencionadas por nós sob a autoridade de alguns homens do passado que o leitor pode desaprovar e que o ouvinte pode achar detestável por não encontrar nada confiável e nenhum significado real. Nesses casos, ele deve saber que não é nossa culpa que tais informações cheguem a ele, mas de alguma pessoa que nos transmitiu. Nós somente reportamos o que nos foi reportado (ȚABARI, 1998, vol 1, p. 171).

A passagem é relevante pois demonstra o interesse do escritor em mostrar ao leitor que há isenção em sua tarefa e que seu trabalho não é de criação ou de interpretação, mas de simples coleta e agrupamento de relatos. Essa preocupação parece ter ganhado mais força depois que os textos de hadīth tomaram uma dimensão mais forte como guia da comunidade e as críticas dos muhaddīth se fortaleceram. Ibn Isḥaq, por exemplo, utilizava isnād em seu trabalho, mas não demonstrava preocupação em citar cadeias completas e não parece ter se esforçado para não dar sua opinião ou para evitar raciocínios individuais em sua Sïrah. ${ }^{13}$

No entanto, mesmo que essas obras sejam compostas por compilações de relatos anteriores, acreditamos que o fator subjetivo está presente no trabalho desses estudiosos e não deve ser desconsiderado, já que as estratégias usadas para seleção e organização desses relatos podem dizer muito sobre a obra final. Robert Hoyland tomou emprestado um termo utilizado por Northrop Frye e popularizado por Hayden White e chamou de emplotment a forma como os eventos são configurados nesses textos de forma que produzam significado e sugere que esse processo é necessariamente subjetivo. Para ele, por mais que o escritor usasse as akhbār como base, era ele quem avaliava o material, dava forma e coerência e criava uma ordem narrativa (HOYLAND, 2006, p. 25-26).

A questão mais fundamental nesse sentido é o processo de seleção dos relatos. O que determina quais narrativas farão parte do trabalho final e quais ficarão de fora são quesitos puramente subjetivos. Em um dos poucos momentos da tārīkh em que Ṭabari dá sua opinião de

\footnotetext{
${ }^{13}$ Segundo Khalidi, é possível detectar reflexões pessoais e comentários nas obras de Isḥaq e as isnād muitas vezes são usadas somente para dar suporte a essas reflexões. KHALIDI, 1994, p. 36.
} 
forma aberta, ele diz: "Quanto aos outros narradores desses eventos, eles contam muitas coisas, algumas repugnantes que me recuso a repetir" (ȚABARI, 1990, vol. 15, p. 68). Esse é somente um exemplo que podemos usar para mostrar que a subjetividade está implícita na atividade de compilação desses autores. O compilador pode escolher, por exemplo, somente transmissores que compartilham um mesmo ponto de vista do acontecimento ou, por outro lado, escolher incluir versões diferentes de um mesmo evento.

Outra prática comum que demonstra certo processo criativo são isnād coletivas. Vejamos um trecho da biografia de Muhammad de Wāqidī (m. 207/822): "Cada um de meus informantes relatou parte da história, alguns sabendo mais do que outros sobre isso, e eu combinei tudo que eles me disseram" (WAQIDI apud HOYLAND, 2006, p. 26). Nesse caso, ele usa várias $a k h b \bar{a} r$ para criar uma outra final e, nesse processo, pode considerar informações e desconsiderar outras de acordo com o que pretende com aquela narrativa. Além dessa, há outras estratégias que por vezes são usadas para dar maior ou menor ênfase a alguma informação específica, como é o caso da repetição de relatos idênticos com isnād diferentes e o alongamento ou abreviação dos relatos.

O outro problema a que nos referimos acima é a respeito da autenticidade das informações que temos sobre as origens do Islã. Como dissemos, os relatos dos acontecimentos dos primeiros anos da comunidade muçulmana só começaram a ser produzidos no final do primeiro século $\mathrm{AH}$ e, mesmo esses, só sobreviveram através de textos escritos posteriormente. Assim, se ninguém escreveu sobre aquele período por muitas gerações, como as informações sobreviveram ao tempo? Como os historiadores contemporâneos podem ter certeza que esses relatos que chegaram até nós não são criações posteriores?

Os historiadores ocidentais atualmente convergem em reconhecer muitas contradições e problemas nos textos do período clássico e acreditam que parte desse material não circulava no período dos acontecimentos, mas eram fabricações posteriores ligadas a $i s n a \bar{d}$ verossímeis. No entanto, alguns desses pesquisadores acreditam que todo o material produzido pelos muçulmanos sobre as origens do Islã deve ser desconsiderado porque dizem muito mais sobre seu momento de produção do que de fato sobre o período que afirmam narrar. Podemos citar como exemplo os historiadores estadunidenses Patricia Crone e Michael Cook, que escreveram em 1977 o livro Hagarism: The Making of the Islamic World em que defendem, e colocam em prática, a noção de que os estudos dos primeiros anos do Islã devem se basear em fontes contemporâneas aos eventos que pretendem analisar. Como esse não é o caso das fontes 
islâmicas, eles consideram que elas devam ser totalmente desconsideradas (COOK; CRONE, 1977, p. 3).

Crone explica sua rejeição dos textos islâmicos na introdução de seu livro lançado três anos mais tarde, Slaves on Horses: The Evolution of the Islamic Polity, em que argumenta que o fator ficcional desse material pode ser explicado por dois motivos: as circunstâncias em que eles foram criados e o método de transmissão. As circunstâncias foram de uma mudança brusca em todos os aspectos da sociedade, incluindo em questões básicas como estruturação social e o ambiente em que viviam, o que causa também uma transformação rápida na forma de significação do passado. O método de transmissão é, ela diz, aquele em que "transmissores memorizavam, não narrativas coerentes ou componentes delas, mas declarações isoladas, relatos curtos de atos de algumas pessoas e breves referências a eventos históricos" (CRONE, 1980, p. 5). Em sua opinião, essas características do método de transmissão, acrescentando-se também o fator oral desse método, podem causar uma alteração nas informações transmitidas, seja porque as partes podem ser facilmente retiradas de seu contexto, ganhar um novo significado ao terem modificadas poucas palavras ou porque podem ser totalmente esquecidas. Une-se a isso o fato de que a autora acredita que os seguidores imediatos do Profeta dificilmente se dedicavam à memorização de hadīth e isso só começou a ser feito em meados do califado omíada, um momento em que a comunidade estava exposta tanto a conflitos internos - criados em sua maioria durante a primeira guerra civil que aconteceu entre os anos de 35-40/656 e 661 - quanto a polêmicas externas, diante do confronto de ideias com outras comunidades monoteístas devido à expansão (CRONE, 1980, p. 6). Com esses argumentos ela defende que tais textos históricos são "um monumento de destruição e não de preservação do passado" (CRONE, 1980, p. 7) e, por isso, não devem ser utilizados como fonte para sua reconstrução ${ }^{14}$. Segundo Donner, essa foi uma abordagem bastante comum entre os historiadores do Islã ao longo das décadas 60 a 90 do século passado, tendência que o motivou a analisar novamente as fontes resultando na obra a que já nos referimos nesse trabalho. Ele chama a forma como esses autores lidam com essa documentação de "abordagem cética" pois, em sua opinião, leva-se ao extremo a noção de crítica documental a ponto de duvidar que qualquer

\footnotetext{
${ }^{14}$ Nesse mesmo texto, Crone faz uma diferenciação entre tradição religiosa, que seriam todos esses textos que aqui chamamos de hadīth e históricos, e tradição tribal, que seriam aqueles que apresentam lendas de famílias e tribos. De acordo com ela, o segundo material não sofreu tão fortemente as transformações em consequência do turbilhão de conflito político-religioso em que a comunidade se acometeu. No entanto, mesmo que esse material pudesse ser usado para os estudos dos primeiros anos do Islã, a autora observa que ele diz muito pouco sobre o que o historiador se interessa porque tem maior enfoque em indivíduos e suas ações do que nos acontecimentos mais gerais. CRONE, 1980, p 9-10.
} 
documento islâmico possa ser útil para acessar informações históricas do período a que se referem. Sua crítica a essa abordagem se baseia principalmente na falta de evidência que confirme que os acontecimentos dos primeiros anos do Islã tenham sido de fato diferentes do que esses textos nos dizem e que o simples fato de notar que há contradições e evidências de interpolações posteriores não prova que esse passado tenha sido totalmente apagado e substituído por algo completamente fabricado (DONNER, 1998, p. 16).

Ainda segundo Donner, uma característica importante desses textos, quase sempre desconsiderada pela abordagem cética, é que obras escritas por membros de diferentes grupos político-religiosos que compunham a comunidade desde pelo menos a já referida guerra civil concordam em muitos pontos a respeito dos acontecimentos do período. A falta de consenso entre textos provenientes de diferentes grupos está muito mais relacionada à interpretação e à significação dos acontecimentos do que à forma os eventos propriamente ditos são narrados (DONNER, 1998, p. 286). Além disso, o autor rejeita a ideia de haver existido autoridades capazes de destruir toda memória daquele passado, fosse ela transmitida de forma escrita ou oral, em todos os cantos do território islâmico, em prol da produção de uma narrativa totalmente nova que seria criada em função dos objetivos dessas autoridades (DONNER, 1998, p. 27).

Donner desenvolve sua argumentação em torno da defesa da utilização dessas obras como fontes históricas a partir da análise dos temas que aparecem com frequência nos textos históricos do período. Como mencionamos anteriormente, a premissa do autor é que o interesse pela história se desenvolveu entre os árabes juntamente com a concepção de sua identidade como muçulmanos, e sua escrita foi uma das formas de legitimação utilizadas por eles. De acordo com essa argumentação, ele defende que muitos temas que encontramos nos textos a que temos acesso, ou seja, aqueles escritos a partir do século III/IX, surgiram bem antes, no contexto mesmo do empenho dos muçulmanos para se definirem como uma comunidade distinta de outras e do confronto entre grupos internos e sua busca para se legitimarem como líderes uns dos outros.

Alguns dos temas identificados são, por exemplo, ummah (comunidade islâmica), nubuwa (profecia), futūh (conquistas) e fitnah (guerra civil). Segundo ele, ummah e nubuwa desempenham o papel de defender o status de Muhammad como verdadeiro profeta e fundador de uma comunidade e estabelecer diferenças entre a comunidade islâmica e os grupos aos quais seus membros costumavam pertencer antes do aparecimento das mensagens do profeta (DONNER, 1998, p. 160 -166). O tema futūh parece ter começado a se desenvolver desde o fim do primeiro século $\mathrm{AH}$ e seu objetivo é contar a forma como surgiu a hegemonia dos 
muçulmanos sobre os não muçulmanos e, dessa forma, justificá-la (DONNER, 1998, p. 174182).

O tema fitnah, por sua vez, descreve como a liderança da comunidade foi conquistada ou perdida por determinados grupos e pode ser narrada com o objetivo de convencer o leitor de que o curso dos acontecimentos foi uma confirmação da vontade divina ou, por outro lado, pode ser uma lamentação sobre como o grupo legítimo foi privado de seu direito (DONNER, 1998, p. 184-190). Para Donner, a existência desse tema nos textos posteriores pode servir para refutar a argumentação da chamada "escola cética". É possível notar nesses textos um foco na liderança dos quraysh (tribo dos coraixitas), que no momento em que os textos foram escritos já haviam se firmado como grupo de liderança. No entanto, mesmo que se possa argumentar que essa predominância dos quraysh tenha sido uma fabricação posterior, as reivindicações pela liderança da comunidade de outros grupos não-quraysh não foram apagadas e ainda aparecem nas fontes (DONNER, 1998, p. 284-285).

\section{CONCLUSÕES}

Este trabalho se concentrou em três problemas principais presentes na historiografia contemporânea que se dedica aos estudos dos primeiros séculos do Islã: o problema da consciência histórica entre os árabes, a questão da autoria das obras historiográficas islâmicas clássicas, e o problema da autenticidade das informações que essas obras nos fornecem. $\mathrm{O}$ debate acerca dessas três questões se deve, em maior ou menor grau, ao fato de que pouco material árabe pré-islâmico e dos primeiros anos do Islã chegou até nós.

A respeito do início da consciência histórica entre os árabes, acreditamos que esse seja um problema sem solução aparente. Se por consciência histórica entendermos a ciência de que o tempo traz transformações para a sociedade e que há algo que já foi, algo que é e algo que ainda será - reflexo da noção básica de nascimento, vida e morte - seria possível afirmar que alguma sociedade não possui ou não possuiu consciência histórica? Ou ainda, mesmo que a resposta da primeira pergunta fosse positiva, poderia o historiador reconstituir com algum nível de precisão o surgimento dessa consciência? Concordamos com Paul Veyne quando diz que o que possui nascimento é o gênero histórico e não a consciência histórica (VEYNE, 1978, p. 46).

Assim, nos parece mais proveitoso pensar não em consciência histórica, mas em consciência historiográfica. Essa abordagem levantaria questões mais concretas cujas respostas podem ser buscadas nos documentos. Deixaríamos de pensar em quando a sociedade começou 
a se perceber como algo inserido no tempo e suscetível a transformações que sua passagem implica e começaríamos a pensar nas motivações que ela teve para começar a investigar seu passado e elaborá-lo de forma narrativa e racional. A contribuição de Donner nos parece significativa ao sugerir que, no caso dos árabes, o início da narração de seu passado surgiu com um propósito bastante prático, se constituiu como uma ferramenta de legitimação e surgiu em um contexto de desenvolvimento da concepção deles próprios como muçulmanos, ou seja, de formação de uma identidade de si mesmos como pertencentes a uma comunidade monoteísta marcadamente diferente das outras.

Outro ponto importante do trabalho de Donner é que, ao questionar a noção de que o interesse pela investigação do passado é inerente ao homem e defender que ele surge em contextos históricos específicos para atender às demandas da sociedade, o autor demonstra que o aparecimento das narrativas dos primeiros anos do Islã parece ser natural se pensarmos que aquele era o momento de formação de uma tradição histórica. A identificação da origem de uma tradição é necessariamente retrospectiva e surge sempre em um momento em que o contexto posteriormente identificado como originário já foi transformado. As rupturas e transformações experienciadas pela sociedade são o fator primordial para que se comece a olhar para o passado para buscar referências (tanto no âmbito prático quanto no âmbito narrativo) do que se deve preservar ou abandonar. Não seria necessário, por exemplo, contar a história de Muhammad, suas mensagens e seus atos se a forma de vida proposta por ele tivesse tido total êxito ou se não tivesse havido rupturas com o contexto em que ele viveu.

Uma grande ruptura aconteceu com a morte de Muhammad, mas a comunidade parece ter se recuperado de forma razoavelmente rápida e os governos dos dois primeiros califas aparecem nas fontes como um período em que a comunidade permaneceu coesa e teve sucesso em caminhar pelo caminho proposto por Muhammad. O que nos parece ser a maior ruptura com o modo de vida ideal daquela comunidade tem início no ano 35/655-656 com a revolta de grupos da própria ummah contra o califa 'Uthmān, culminando em seu assassinato. Naquele momento começou a se romper a unidade da ummah, construída e defendida por Muhammad. Depois desse episódio, 'Ali, primo e Companheiro do Profeta, assumiu o califado, mas ao longo dos cinco anos de seu governo sua legitimidade como líder nunca foi reconhecida por alguns grupos da comunidade. No ano 40/661, 'Ali também foi assassinado por um grupo de muçulmanos que fazia oposição a ele. A dinastia Omíada, que governou a comunidade desde aquele ano até a revolução abássida em 132/750, foi quem estabeleceu novamente uma liderança unificada em todo o califado, mas não o fez sem grande resistência de outros grupos 
${ }^{15}$. É exatamente nesse período, posterior a uma grande ruptura e em um contexto de intenso conflito entre grupos que se consideravam legítimos para a liderança da comunidade, que Donner identifica nos textos as primeiras referências a Muhammad e sua história, que, segundo ele, datam nos anos 60 e 70 da hégira (DONNER, 1998, p. 88) ${ }^{16}$.

Esse caminho nos leva à questão apresentada aqui através dos trabalhos de Crone e Cook, que defendem a não utilização dos textos islâmicos por não se tratarem de documentos contemporâneos aos acontecimentos e terem sido elaborados em um contexto de intenso conflito político-religioso, o que os leva a defender que o estes são, portanto, uma "destruição" e não uma "preservação" das informações do passado. O raciocínio apresentado acima refuta a ideia de que o aparecimento tardio dos textos históricos entre os árabes signifique necessariamente que as informações contidas ali são simples invenções posteriores por parte de grupos político-religiosos dominantes no período e que toda a memória "real" dos acontecimentos tenha sido apagada em função dos interesses desses grupos. Não podemos, no entanto, desconsiderar que esses textos são construções racionais sobre o passado e, como tais, são elaboradas a partir de um ponto de vista. Mas seria muito diferente se esses textos tivessem sido construídos contemporaneamente aos acontecimentos? Eles seriam mais neutros? Em nossa opinião, a resposta é negativa, já a questão do ponto de vista ainda estaria presente.

Marc Bloch já sugeria há mais de meio século que deixássemos de lado a noção positivista do século XIX de que o resultado do ofício do historiador deva ser a recuperação de uma verdade fechada sobre o passado e, dessa forma, defendia que não há nenhum vestígio dos homens no tempo que não possa ser utilizado como documento para análise do passado (BLOCH, 2002). Assim, acreditamos que ao invés de discutirmos se devemos ou não utilizar tais textos como fontes históricas para os estudos do período que elas narram, deveríamos nos dedicar a pensar em metodologias e modelos através dos quais podemos compreender suas particularidades e utilizá-las de forma crítica. Não acreditamos, portanto, que devemos usar as fontes concebidas fora do contexto islâmico em detrimento dos textos produzidos pelos muçulmanos, mas ambos de forma comparada, podendo recorrer ainda a trabalhos

\footnotetext{
${ }^{15}$ Um exemplo de resistência ao governo omíada é a Batalha de Karbala em 61/680. Ao longo de todo o governo de 'Ali (656-661), ele sofreu com a resistência dos sírios, sob comando de Mu' āwiyah, que nunca o reconheceram como califa. Após sua morte, seu filho mais velho e segundo imam do xiitas, Husayn, foi declarado califa pela parte da comunidade aliada, mas seis meses depois, Husayn estabeleceu um pacto com Mu'āwiyah em que reconhecia o governo do omíada com a condição de ser convocado um conselho para escolher seu sucessor após sua morte. Husayn morreu antes de $\mathrm{Mu}$ 'āwiyah, que, por sua vez, foi sucedido por seu filho, Yazīd, sem a convocação do conselho. Em 61/680, Hasan, filho mais novo de Ali e terceiro imam dos xiitas, declarou guerra contra Yazīd, mas ele e seus líderes foram mortos na batalha final. Sobre a Batalha de Karbala ver (RICHARD, 1995, p 27-29)

${ }^{16}$ Conferir nota 88 na mesma página.
} 
arqueológicos. O problema da autenticidade das informações contidas nas fontes é uma questão com a qual todos os historiadores precisam lidar e acreditamos que abrir mão de um conjunto tão vasto como os textos históricos islâmicos não seja a saída para resolvê-lo.

A terceira questão trabalhada nesse texto, o problema da autoria, parece-nos ser central para pensarmos em como abordar metodologicamente esses textos. Como referido anteriormente, aqueles que compilaram as $a k h b \bar{a} r$ em livros tinham o interesse em mostrar para seu leitor que sua opinião não estaria contida em sua obra, que se tratava somente de uma simples reunião das informações que chegaram até eles. No entanto, o simples fato de selecionálos e organizá-los de forma que produzam significado já é um processo subjetivo. Um exemplo de um relato em que o ponto de vista do autor está bastante claro é o de Sayf b. 'Umar sobre o assassinato do califa Uthmān presente na tārīkh de Țabari. Sayf nos apresenta um quadro em que Uthmān é pintado de forma quase perfeita e tem a seu lado os grandes homens e mulheres da comunidade. Do outro lado estão seus opositores, que segundo o relato, não respeitam a religião e nem a comunidade e são guiados por desejos mundanos e egoístas. Ao longo de sua narrativa o leitor tem a impressão de que o final da trama será positivo e que Uthmān não será morto, já que é narrado como um homem justo, cuja imagem por si só é capaz de fazer com que os rebeldes recuem. É um homem forte e mesmo com sua idade avançada está disposto a pegar sua espada e seu escudo para lutar contra aqueles que o atacam, além de ter a seu lado grandes homens, exemplo de piedade e correção, que também estão dispostos a lutar por ele até a morte (ȚABARI, 1990, vol. 15). Sua narrativa é feita para comover e tem sucesso: quando o desfecho final é narrado, o leitor fica com um sentimento de extrema injustiça.

Assim, acreditamos que esses textos carregam características subjetivas de seus escritores e muitas vezes têm implícitas as opiniões que se negam declarar abertamente. No entanto, concordamos que em textos escritos posteriormente, após o fortalecimento da hadīth na sociedade, a presença dos traços do autor em seu trabalho pode ser um pouco mais sutil. Tabari, por exemplo, é conhecido por seguir com grande rigor o modelo de hadīth em sua tārīkh, com utilização de isnād completas e apresentação de vários relatos sobre o mesmo assunto, muitas vezes contendo versões diferentes do acontecimento. Mesmo nesse caso, acreditamos que o fator subjetivo não deve ser ignorado pois, ainda que de forma mais sutil, a presença de um autor que seleciona as akhbār e as organiza de acordo com seus objetivos ainda existe. Percebe-se em sua tārīkh, por exemplo, a interrupção de alguns relatos mais longos para conseguir apresentar outras versões de diferentes informantes sobre o mesmo evento ${ }^{17}$, o que

${ }^{17}$ Um exemplo das muitas vezes em que isso acontece por ser visto em TABARI, 1996, vol. 17, p. 80. 
nos mostra que seu trabalho também não era de simples coleta e reunião de tudo o que recebia. As conclusões a que se pode chegar sobre essas características citadas podem ser inúmeras e variam de caso a caso. Em algumas obras pode ser possível identificar o grupo político-religioso ao qual o autor pertencia; em outros, pode se concluir que o autor realmente tentava ser mais isento e não indicar suas opiniões, no entanto, mesmo no segundo caso, acreditamos que essa característica, por si só, já constitui marca subjetiva daqueles que a compuseram.

Compreender essas características dos textos e seu processo de produção nos parece imprescindível para pensarmos em formas de abordá-los metodologicamente. Ao trabalharmos com esses textos, não estamos lidando com simples vestígios deixados pelos homens enquanto viviam suas vidas. Elas são elaborações textuais pensadas de forma racional para dar significado ao passado e surgem de um contexto social específico. Assim, se consideramos o processo de produção desses textos como um processo subjetivo de elaboração do passado e a pessoa responsável por sua produção como autor consciente dessa obra, nos parece apropriado chamar o autor de historiador, as obras de história e o processo de produção de historiografia. A definição de Rosenthal de historiografia islâmica pode ser útil para nos ajudar a pensar sobre o assunto: "Historiografia islâmica inclui aqueles trabalhos que os muçulmanos, em um dado momento de sua história literária, consideraram trabalhos históricos e que, ao mesmo tempo, contém uma quantidade razoável de material que pode ser considerado histórico de acordo com nossa [ocidental e moderna] definição de história" (ROSENTHAL, 1968, p. 17). Evidência de que essas obras escritas nos primeiros séculos da hégira são consideradas obras de história pelos próprios muçulmanos pode ser notada quando Ibn Khaldūn escreveu, em 1377, seu Kitāb al'Ibar (Livro das Lições). Nele, Khaldūn propôs um método novo de investigação e escrita da história se contrapondo ao método de muitos desses autores aos quais nos referimos aqui, a quem ele chama de "historiadores" (KHALDUN, 1967, 5-6). Quanto à segunda parte da afirmação de Rosenthal, acreditamos que o fato de identificarmos um autor consciente que constrói uma narrativa sobre o passado seja uma evidência de que há nessa obra características que os historiadores contemporâneos consideram fundamentais em uma obra de história. Essas características devem ser analisadas caso a caso em estudos mais circunscritos, mas o que queremos defender aqui é que tais obras são elaborações de uma memória sobre o passado, organizada de forma coerente e mais ou menos homogênea. E, como toda narrativa histórica, é necessariamente uma construção e deve ser analisada como tal.

Entendemos, assim, que um historiador que tome essas obras como fontes para seus estudos deve pensar seu trabalho inserido no campo da história da historiografia. Essa 
perspectiva sugere outras duas possibilidades de utilização dos textos para o campo dos estudos da história além daquela já discutida acima, que é a utilizá-las de forma comparada a outras como fontes para informações do período que elas narram. Abre-se a possibilidade de utilização desses documentos para tomar o próprio processo de escrita da história entre aquelas pessoas como objeto de estudos, a fim de compreender as motivações, suas formas e seus usos. Outra possibilidade é o uso das fontes para os estudos do tempo em que foram escritas, já que podem conter muitas informações, explícitas ou implícitas, sobre as configurações políticas, querelas religiosas ou jurídicas, entre outros possíveis objetos de interesse para os historiadores.

\section{REFERÊNCIAS}

AL-TABARI, Muhammad ibn Jarir. Tārīkh al-Rusul wa al-Muluk. Various translators. Albany: State University of New York Press, 1989, 1990, 1996. Vols. 1, 15 e 17.

DE BLOIS, F.C. Tarikh. In: BEARMAN, PJ.; BIANQUIS, TH.; VAN DONZEL, E; HEINRIGHS, W. P. (Eds). The Encyclopaedia of Islam. Leiden: Brill, 2000. Vol 10, p 257302.

BLOCH, Marc. A Apologia da História ou o Ofício do Historiador. Rio de Janeiro: Jorge Zahar Editor, 2002.

COOK, Michael; CRONE, Patricia. Hagarism: The Making of the Islamic World. Cambridge: Cambridge University Press, 1977.

CRONE, Patricia. Introduction. In: CRONE, Patricia. Slaves on Horses: The Evolution of the Islamic Polity. Cambridge: Cambridge University Press, 1980, p. 3-28.

DONNER, Fred McGraw. From Believers to Muslims: Confessional Self-identity in the Early Islamic Community. Al-Abhath: Journal of the Faculty of Arts and Sciences. Beirut. Vol 50-51, p. 9-53. 2003.

DONNER, Fred McGraw. Narratives of Islamic Origins: The beginnings of Islamic Historical Writing. New Jersey: The Darwin Press, 1998. 
HOYLAND, Robert. History, fiction and authorship. in the first centuries of Islam. In:

BRAY, Julia. Writing and representation in Medieval Islam. New York: Routledge, 2006, p. $16-46$.

KHALDUN. Al-Muqaddimah. Translated by Franz Rosenthal. Princeton: Princeton University Press, 1967.

KHALIDI, Tarif. Arabic Historical Thought in the Classical Period. Cambridge:

Cambridge University Press, 1994.

QURESHI, I. H. Historiography. In: SHARIF, M. M. A History of Muslim Philosophy. Kempten: Allgauer Heimatverlag, 1966, p. 1195-1218.

RICHARD, Yann. Shi'ite Islam. Cambridge: Blackwell Publishers, 1995.

ROBINSON, Chase F. Islamic Historiography. Cambridge: Cambridge University Press, 2003.

ROSENTHAL, Franz. A History of Muslim Historiography. Leiden: Brill, 1968.

SCHOELER, G. The Oral and the Written in Early Islam. New York: Routledge, 2006.

VEYNE, Paul. Como se Escreve a História. Brasília: Editora UnB. 1978.

ARTIGO ENVIADO EM: 02/01/2017

ARTIGO ACEITO PARA PUBLICAÇÃO EM: 15/06/2017

Oficina do Historiador, Porto Alegre, EDIPUCRS, v. 11, n. 2, jul./dez. 2018, 